\title{
La educación militar a la luz del posconflicto ${ }^{1}$
}

https://doi.org/10.21830/9789585241459.10

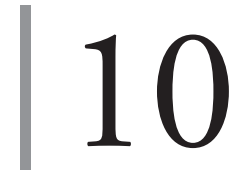

\author{
Álvaro Méndez Cortés ${ }^{2}$ \\ Escuela de Armas Combinadas del Ejército
}

\section{Resumen}

Antecedentes: el escenario cambiante que implica la firma del acuerdo de paz en Colombia es un reto para el Ejército Nacional, que ha demostrado su capacidad de respuesta, defensa y garantía de la seguridad nacional. Ahora asume con profesionalismo los desafíos doctrinales y operacionales que le plantean el posconflicto y los mandatos legales para integrar la paz en sus procesos de formación. Objetivo: el documento analiza la educación militar, sus implicaciones y retos a la luz del posconflicto. A partir de los resultados obtenidos, se desarrolla una propuesta preliminar con el fin de articular los procesos educativos de las Fuerzas Militares. Materiales y métodos: se hizo una indagación documental que se orientó a identificar y caracterizar las finalidades de formación, los componentes del sistema educativo y las transiciones en la consolidación del Ejercito Nacional. También se analizaron los documentos institucionales y los postulados legales de la Constitución Nacional que fundamentan la misión de la Fuerza y sus compromisos con el estado social de derecho. Por eso se hizo énfasis en las directrices del mando militar, toda vez que orientan los esquemas de educación militar para el posconflicto.

Resultados: con base en el análisis documental se plantean posibles cursos de acción frente al compromiso de implementar la Cátedra para la Paz y formar al militar en un escenario que es novedoso para la institución después de más de sesenta ańos de conflicto. Conclusiones: finalmente el compromiso es del militar como ciudadano que entienda la realidad cambiante del país y que ya está saliendo del conflicto, las escuelas de formación en el replanteamiento de los pensum académicos, los altos mandos para tomar la decisión de dar el cambio en la estrategia

1 Capítulo de libro que parte de los resultados del proyecto de investigación Práctica Pedagógica en el Ejército Nacional: Reflexiones en torno a la Formación y la Investigación, del Grupo de Investigación para la Capacitación Militar (GICAM) de la Escuela de Armas Combinadas (ESACE), registrado con el código COL0160714 de Minciencias. Los puntos de vista y los resultados de este estudio pertenecen al autor y no reflejan necesariamente los de las instituciones participantes.

2 Sargento Mayor de Comando de la Reserva Activa del Ejército Nacional. Administrador de Empresas de la Universidad Nacional Abierta y a Distancia (Unad). Administrador de Seguridad y Salud Ocupacional, especialista en Docencia Universitaria y magíster en Educación de la Universidad Militar Nueva Granada. Orcid: https://orcid.org/0000-0002-0980-8087, contacto: alvaro.mendezcortes@cedoc.edu.co 
educativa y la sociedad para que vea en su Ejército una institución garante de los acuerdos y la búsqueda de la paz.

Palabras claves: cátedra; Colombia; doctrina; educación; militar; paz; posconflicto.

\section{Introducción}

El texto hace una aproximación a la educación para el posconflicto que acompañará la cátedra en las escuelas militares desde un enfoque apropiado para el militar del siglo XXI. Para esto se toma como referencia autores y especialistas que han presentado sus aportes desde años atrás hasta el presente en este campo.

El desarrollo de las Fuerza Militar siempre ha estado de la mano con la academia y el escenario social que impera en el momento. En el caso colombiano, es evidente que la formación académica y el entrenamiento del integrante de la Fuerza Pública han sido influidos por los fenómenos sociales característicos de cada etapa del desarrollo republicano.

Desde luego que la experiencia docente también está enmarcada en los contextos sociales e históricos, de manera que es una práctica social compleja que tiene diversas perspectivas de acuerdo con el momento histórico (Vergara, 2016.). Particularmente en Colombia, los vaivenes de la política del siglo XIX, el enfrentamiento por el poder entre dos corrientes ideológicas, el conflicto nacido de estas confrontaciones, la aparición de los grupos insurgentes y los procesos de negociación han marcado el devenir de la educación militar.

Luego de la Segunda Guerra Mundial se acentuó la dependencia a la doctrina norteamericana. Más adelante, en los años 50 la influencia es total y a ello se suma la participación de Colombia en la guerra de Corea, de la cual regresó con altos honores y reconocimientos por el excelente desempeño que tuvieron sus combatientes de Infantería. Precisamente, de la mano de ese contingente guerrero llegaron nuevas doctrinas y propuestas de mejora y estructuración de una formación militar.

Así, durante más de 60 años se desarrolló la teoría del "enemigo interno"3 y como consecuencia las Fuerzas Militares se involucraron sistemáticamente en la confrontación entre conciudadanos. Esto produjo que la formación académica, pedagógica y de guerra en la educación militar fuera diseñada y pensada para confrontar este tipo de adversario.

3 Concepto de construcción política que surge inicialmente como la identificación de un "enemigo común": el comunismo internacional, que fue interpretado como una amenaza para "la seguridad colectiva de los Estados" bajo influencia de los Estados Unidos (Ahumada, 2007). 
Con el advenimiento del siglo XXI, y en concordancia con la Constitución de 1991, se inició en la patria un proceso en el cual se quiere proveer al ciudadano un país en paz desde el mismo ordenamiento constitucional. Al respecto, resulta significativo que el 25 de mayo de 2015 se expidió el Decreto 1038, que reglamenta la Ley 1732 de 2015 y que corresponde a la implementación de la Cátedra de la Paz en las instituciones educativas públicas y privadas de Colombia; por supuesto ahí está incluida la educación del militar. La ley indica que la cátedra deberá estar articulada con áreas del conocimiento como ciencias sociales, ciencias naturales o educación ética y que pretende contribuir a la formación de competencias ciudadanas en los estudiantes.

Esta normatividad responde al hecho incontrovertible de que Colombia tiene que prepararse para enfrentar los retos del postconflicto. Schultze-Kraft (2012), citados por Rettberg (2012), así lo indicaban: "Hasta el momento, no se ha visto que en Colombia se haya planteado de manera consciente y pública la pregunta acerca de la cuestión militar en un eventual postconflicto" (p. 423). Y esa cuestión que refiere el autor tiene que ver con la educación, pilar fundamental de un proceso exitoso y aspecto sobre el cual versa el presente escrito.

También es importante señalar que, aunque el Estado colombiano no da fin al conflicto, pues se mantienen algunos grupos en la ilegalidad, sí hay espacios o escenarios de posconflicto sectorizado. Al respecto, Ugarriza (2013) argumenta que "no puede haber construcción de paz en medio del cruce del fuego entre actores. Pero sí podría hablarse de construcción de paz en zonas y espacios que no estén en medio de las hostilidades. Es decir, cuando existen ventanas de postconflicto". Es decir, no es óbice para dar inicio a propuestas de educación en las Fuerzas Militares que incluyan la cátedra y que se vayan madurando para ser aplicadas en todo el estamento educativo castrense.

La escuela es el espacio por excelencia donde se promueven los cambios sociales y de la cultura, es el aliado estratégico del posconflicto y, pues una vez se dan los acuerdos de paz e inicia esta etapa, la academia tiene la responsabilidad de orientar su quehacer formativo hacia la reconstrucción social en un ambiente de paz. Como afirma Zurbano (1998), "la educación para la paz será uno de los objetivos prioritarios de la escuela del futuro" (p. 14). En el caso de las Fuerza Militares, sus escuelas no se pueden sustraer de esta responsabilidad, sobre todo porque tienen un conglomerado social que, por encima de los demás respecto al cumplimiento del mandato constitucional, debe tener claro el significado del posconflicto.

De acuerdo con Zurbano (1998), ser docente de una escuela militar marca una diferencia total debido a que el militar es un alumno comprometido, es abierto, 
entregado, de buen humor, por decirlo así, con buena actitud, pues por su formación es disciplinado, y extremadamente obediente. Sin embargo, agrega el autor, esta población se percibe algo apartada de la realidad nacional, excepto casos especiales, pues solo le interesa su campo militar y nada más.

En el medio militar colombiano son escasos los estudios que se han realizado sobre este tema, bien sea por falta de interés de los investigadores o por el difícil acceso que tienen al sistema educativo del entorno castrense, sumado a que dentro de la estructura militar no es común estudiar temas de carácter social, entre ellos lo atinente a la educación.

\section{Aspectos legales}

A continuación, se presentan los principales referentes legales que enmarcan una propuesta de educación militar para el posconflicto.

1. Constitución nacional de Colombia

a. Artículo 41: "En todas las instituciones de educación, oficiales o privadas, serán obligatorios el estudio de la Constitución y la Instrucción Cívica. Así mismo se fomentarán prácticas democráticas para el aprendizaje de los principios y valores de la participación ciudadana".

b. Artículo 67: "La educación es un derecho de la persona y un servicio público que tiene una función social; con ella se busca el acceso al conocimiento, a la ciencia, a la técnica, y a los demás bienes y valores de la cultura. La educación formará al colombiano en el respeto a los derechos humanos, a la paz y a la democracia; y en la práctica del trabajo y la recreación, para el mejoramiento cultural, científico, tecnológico y para la protección del ambiente".

c. Artículo 222: "La ley determinará los sistemas de promoción profesional, cultural y social de los miembros de la Fuerza Pública. En las etapas de su formación, se les impartirá la enseńanza de los fundamentos de la democracia y de los derechos humanos.

La implementación del Acuerdo final para la terminación del conflicto y la construcción de una paz estable y duradera involucra diferentes sectores, entre ellos el educativo, por tanto, este debe dar cumplimiento a lo pactado. En consecuencia, se deben plantear escenarios de formación en los cuales se ofrezca una cátedra sobre 
"las normas para la terminación del conflicto armado y la construcción de una paz estable y duradera", aspecto que se integró al bloque de constitucionalidad y por tanto forma parte de la Constitución Nacional, así sea en un título transitorio.

- Ley 30 de 1992, la cual organiza el servicio público de educación superior, recoge toda la normatividad previa y emite parámetros específicos.

- Ley 115 de 1994. Por la cual se expide la Ley General de Educación. En el Artículo 5 indica que la educación se desarrollará atendiendo a los siguientes fines: la formación en el respeto a la vida y a los demás derechos humanos, a la paz, a los principios democráticos, de convivencia, pluralismo, justicia, solidaridad y equidad, así como en el ejercicio de la tolerancia y de la libertad.

- Ley 1620 de 2013, denominada Ley de Convivencia Escolar, de orden nacional.

- Decreto reglamentario 1965 de 2013, emitido para reglamentar la Ley de Convivencia Escolar.

- Decreto reglamentario 1038 de 25 de mayo de 2015, a través del cual se reglamenta la Cátedra de la Paz.

- Plan Decenal de Educación 2006-2015, el cual está enfocado a ofrecer educación en y para la paz, la convivencia y la ciudadanía. Ministerio de Educación Nacional.

- Consejo Nacional de la Educación Superior (Cesu). Acuerdo por lo Superior 2034. Propuesta presentada por el Ministerio de Educación Nacional de política pública para la excelencia de la educación superior en Colombia, en el escenario de la paz.

- Ley 1732 de septiembre de 2014, que establece la Cátedra para la Paz en todas las instituciones educativas del país y que debe ser orientada por el área de ciencias sociales e incluir las demás áreas del conocimiento. Esta cátedra, según la ley, se considerada un espacio de conocimiento, reflexión y análisis en temas de violencia, conflicto armado, criminalidad y demás temas inherentes. Busca, entre otros objetivos, que el individuo esté en capacidad de desarrollar acciones por y para la paz.

Aparte de estas normativas, en el Acuerdo final para la terminación del conflicto y la construcción de una paz estable y duradera se hace referencia a la educación en el punto 2: Participación política, apertura democrática para construir la paz. También en el punto 2.2: Mecanismos democráticos de participación ciudadana, donde uno de los apartes indica: 
Pedagogía y didáctica del Acuerdo Final: impulso de programas de formación y comunicación para la apropiación de este Acuerdo, en especial sobre los diseños de participación política y social acordados. Se creará un programa especial de difusión que se implementará desde el sistema de educación pública y privada en todos sus niveles. Se garantizará la difusión del Acuerdo en todos los niveles del Estado. (Oficina del Alto Comisionado para la Paz, 2016, p. 47)

Este acuerdo, que forma parte del bloque de constitucionalidad, establece que se debe crear un programa para difundirlo en el sistema educativo nacional en todos los niveles (primaria, secundaria, técnica, tecnología y universitaria). Dado que las escuelas militares forman parte del sistema de educación nacional, deben dar cumplimiento a este apartado.

De la misma forma, en el ítem 5.2.1 del pacto, Fortalecimiento de los mecanismos de promoción de los derechos humanos, se indica que se debe fortalecer la implementación del Plan Nacional de Educación en Derechos Humanos: "La inclusión del Acuerdo Final y del Informe Final de la Comisión para el Esclarecimiento de la Verdad, la Convivencia y la No Repetición al Plan Nacional de Educación en Derechos Humanos" (República de Colombia, 2016, p. 190).

Este marco normativo evidencia que el ordenamiento jurídico nacional ha enfocado diversas regulaciones en pro de ofrecer al ciudadano colombiano las garantías plenas para que pueda recibir educación relacionada con la paz y el posconflicto.

Ahora bien, con el ánimo de ampliar el referente conceptual, a continuación, se hace referencia a planteamientos sobre educación para la paz que se pueden asimilar al postconflicto (tabla 1 ).

Tabla 1. Conceptualización de educación y paz

\begin{tabular}{ll}
\hline \multicolumn{1}{c}{ Título, Autor } & \multicolumn{1}{c}{ Referencia } \\
\hline $\begin{array}{l}\text { Educación para la paz, una obligación } \\
\text { institucional. Entrevista con Gloria }\end{array}$ & "Educación (de la paz) no puede ser puntual, es decir, \\
Ramírez Hernández, Hilda Villegas & no puede ser una actividad ni un libro o un evento: tiene \\
González (2014) & $\begin{array}{l}\text { que estar presente en todos los espacios institucionales y } \\
\text { estar al tanto de todas las formas de violencia. La cultura } \\
\text { de la paz no es estar en favor de la paz, sino propiciar el }\end{array}$ \\
& respeto y la democracia en el ámbito interno" (p. 10). \\
Bases de una educación para la paz & "La Educación para la convivencia Pacífica es un tema \\
y la convivencia, José Luis Zurbano & transversal. Y los temas transversales no son un capricho \\
Díaz de Cerio (1998) & de una reforma educativa que nos ha tocado vivir. Son \\
& unos temas educativos vitales, decisivos, para el hombre \\
\hline
\end{tabular}




\begin{tabular}{|c|c|}
\hline Título, Autor & Referencia \\
\hline $\begin{array}{l}\text { Bases de una educación para la paz } \\
\text { y la convivencia, José Luis Zurbano } \\
\text { Díaz de Cerio (1998) }\end{array}$ & $\begin{array}{l}\text { de nuestro tiempo. No podemos cerrar los ojos a la } \\
\text { realidad, a la vida. Si no queremos defraudar muy grave- } \\
\text { mente a nuestros alumnos(as), tenemos que apostar } \\
\text { decididamente por los temas transversales. Uno de ellos } \\
\text { es la Paz, la convivencia Pacífica" (142). } \\
\text { "Educar para la paz exige, ni más ni menos, desarrollar } \\
\text { en nuestros alumnos lo más genuino de su persona. } \\
\text { La armonía consigo mismo, con los demás y con el } \\
\text { medio nos lleva frontalmente a la educación integral. } \\
\text { Toda educación será, por tanto, educación para la paz. } \\
\text { Cualquier progreso educativo será una mejora de la } \\
\text { convivencia humana" (p. 24). }\end{array}$ \\
\hline $\begin{array}{l}\text { El desarrollo del currículo y la educa- } \\
\text { ción para la paz, Juan M. Escudero } \\
\text { Muńoz (1999) }\end{array}$ & $\begin{array}{l}\text { "La paz, a su vez, no puede quedar como una bella } \\
\text { aspiración situada en el mundo de las ideas. Si queremos } \\
\text { la paz, si estamos a favor de unas relaciones sociales, } \\
\text { culturales, económicas y políticas, de naturaleza pacifista } \\
\text { hemos de comprometernos en la transformación de los } \\
\text { valores subyacentes a nuestras prácticas sociales" (p. 5-6). } \\
\text { "Educar para la paz no se debería traducir en añadir } \\
\text { nuevos contenidos curriculares y específicos, sino en } \\
\text { un determinado modo de abordar los contenidos exis- } \\
\text { tentes; un determinado estilo social de relaciones entre } \\
\text { profesores y alumnos, así como de los alumnos entre } \\
\text { sí; en un determinado enfoque que permita conectar lo } \\
\text { que se enseńa y corre en la escuela con la realidad social, } \\
\text { cultural y política a la que pertenecen los alumnos y los } \\
\text { mismos profesores" (p. 19). }\end{array}$ \\
\hline $\begin{array}{l}\text { La educación para la paz como } \\
\text { propuesta ético-política de emanci- } \\
\text { pación democrática, Johanna Ospina } \\
\text { (2010) }\end{array}$ & $\begin{array}{l}\text { "Entre la educación y la paz no se había establecido } \\
\text { alguna relación hasta después de la Primera Guerra } \\
\text { Mundial (1914-1918), por ello nació la necesidad de } \\
\text { crear un tipo de educación que contribuyera a superar } \\
\text { las dificultades y hostilidades entre pueblos y naciones" } \\
\text { (p. 93). } \\
\text { "En el abordaje de la educación para la paz, es precisa- } \\
\text { mente este tipo de violencia la que debe ser transformada } \\
\text { y erradicada con el fin de hacer posible la construcción } \\
\text { de un tipo de paz cuyas bases se encuentren bajo los } \\
\text { principios de justicia social y desarrollo sostenible en } \\
\text { igualdad de condiciones" (p. 94). }\end{array}$ \\
\hline
\end{tabular}




\begin{tabular}{l}
\hline Título, Autor \\
\hline El problema de la guerra y las vías de \\
la paz, Norberto Bobbio (2000)
\end{tabular}

Pedagogía y Paz. Instituto de la Paz y los Conflictos de la Universidad de Granada, bajo la dirección del Doctor Mario López Martínez (2010)

Una cultura de paz, Vicenç Fisas (1998)
"La paz puede ser entendida en dos perspectivas: paz interna y paz externa. La paz interna se considera la ausencia, cese o desaparición de un conflicto interno. En relación con lo "interno", este se entiende como un conflicto entre los comportamientos y actitudes de un mismo autor, es decir, incompatibilidades entre el deber y el placer, entre la pasión y la razón, entre el interés propio y el interés ajeno. La paz externa es la ausencia o cese de un conflicto externo, es decir, la ausencia de un conflicto entre individuos y grupos diferentes" (p. 161).

"Podemos definir la pedagogía de la paz como el conjunto de teorías y prácticas educativas orientadas a la construcción de la paz a través de un modelo concreto de educación considerada como un proceso dirigido tanto a los individuos como a la sociedad para que actúen, conforme a los principios de la Cultura de Paz, respetando los derechos humanos, a favor del desarrollo sostenido de los pueblos, la protección y la conservación del medio ambiente, la aspiración y acción en pro del desarme, del desarrollo y la seguridad humana, el fortalecimiento de la convivencia social y la solución no violenta de los conflictos" (p. 2).

"La finalidad inmediata de la pedagogía de la paz comprende el estudio descriptivo (observa, analiza y compara los distintos modelos de educación para la paz en el mundo) y el estudio explicativo (investiga las razones y causas de los fenómenos o hechos que la educación para la paz aborda para orientar teorías y prácticas futuras)" (p. 2).

"Desde la educación para la paz se ha dicho siempre, y con razón, que hemos de educar para la disidencia, la indignación, la desobediencia responsable, la elección con conocimiento y la crítica, es decir, para salirnos de las propuestas de alienación cultural y política" (14).

Fuente: Original del autor.

Estas concepciones permiten dilucidar con mayor amplitud la conceptualización de la educación para la paz y hacen posible entenderla con claridad. No obstante, es necesario tener en cuenta que la paz encierra una serie de componentes conexos sin los cuales difícilmente se puede lograr. Por su parte, la Organización de las Naciones Unidas (ONU, 1984) hace referencia al objeto de la educación en el artículo 26, numeral 2, de la Declaración Universal de los Derechos Humanos: 
La educación tendrá por objeto el pleno desarrollo de la personalidad humana y el fortalecimiento del respeto a los derechos del hombre y a las libertades fundamentales; favorecerá la comprensión, la tolerancia y la amistad entre todas las naciones y todos los grupos étnicos o religiosos, y promoverá el desarrollo de las actividades de las Naciones Unidas para el mantenimiento de la paz.

Esta referencia evidencia que las organizaciones multilaterales tienen identificado de manera clara el concepto de la educación como base sobre la cual se construye el futuro y el desarrollo de los países y a través de ella se confronta la desigualdad y la violencia.

En el contexto colombiano, a pesar del esfuerzo del gobierno nacional aún se evidencia un vacío estructural en cuanto a la implementación de contenidos sobre una cultura de paz dentro del currículo académico del sistema educativo. Así mismo, la paz se ve como un tema estrictamente vinculado con los grupos ilegales, la guerra y el ámbito militar, y no como un tema académico y de responsabilidad social. Como se mencionó, un primer acercamiento al tema de la paz han sido los mandatos de la Constitución Política de 1991, donde se incluye la promoción, el respeto, la defensa de los derechos humanos, la paz y la democracia dentro del escenario escolar. De esta forma, el Ministerio de Educación Nacional "estructuró la estrategia denominada 'propuesta integral de formación ciudadana', la cual con un enfoque pedagógico tenía como objetivo la sana convivencia” (Guerrero \& Osorio, 2017, p. 21).

\section{Posconflicto y educación militar}

La educación, en concepto de Borrero y Alonso (2006), no es más que "un signo indefectible de la pujanza de los pueblos, y por ello abunda en quilates políticos, destinada como está, entre otros fines, a generar el orden de individuos capaces de integrarse de lleno y en paz" (p. 5). Es decir, la educación es orden, es integración y es paz, y a ello le apunta la propuesta de educación para la paz, o esa tal vez es la intención.

Cuando se menciona la educación para la paz o una educación prevista para el posconflicto, se procura una formación que no discrimine, que reconozca la diversidad, entendidos desde la forma de pensar, actuar, de ver el mundo, decidir, creer, discernir y disentir de manera particular, sin ningún temor a ser señalado o estigmatizado. Se tiene la esperanza de que las cosas cambien: la injusticia, la deshonestidad, la corrupción, la violencia doméstica y urbana; que el ciudadano sea más solidario; que haya bienestar y justicia para todos; que la educación sea punto de 
partida inicial para el logro de ese objetivo nacional. Con este propósito es necesario definir estrategias de enseñanza de la paz capaces de contribuir a mantener los pactos que se hicieron en el acuerdo y a generar el cambio social, pero sobre todo a promover la sana convivencia, la solidaridad, la participación, la justicia, en un ambiente que surge del conflicto, el cual ha cobrado innumerables vidas de ciudadanos colombianos (militares, guerrilleros y población civil). No es una tarea fácil, pero es necesaria.

Por esta razón, pensar en el desarrollo de la educación militar a la luz del posconflicto es un compromiso que obliga a que todas las partes se involucren. Al respecto, Zurbano (1998) indica que "la educación para la paz y la convivencia requiere un planteamiento sinérgico: profesores, alumnos, padres, asociaciones $y$, en general, la sociedad debe marcar unos objetivos comunes, consensuados y mantenidos con tesón” (p. 7). Es decir, toda la sociedad debe comprometerse a participar y con base en esto se analizan sus responsabilidades y compromisos dentro del proceso educativo, una tarea que bien se puede realizar dentro del estamento militar.

En cuanto a la pedagogía militar se debe señalar que tiene

como objeto de estudio la formación del militar, investiga la educación militar como fenómeno sociocultural, pero principalmente humano, brindándole un conjunto de bases y parámetros para analizar y estructurar la educación y los procesos de enseñanza y aprendizaje que intervienen en ella. (Ruiz, 2012, p. 168)

En este sentido, la formulación de propuestas educativas y pedagógicas para preparar a la institución militar frente a los escenarios de posconflicto necesariamente tiene que ir más allá de la cita anterior. Se debe plantear desde la visión y misión de la fuerza, y de ahí en cadena descendente hasta las escuelas o centros de formación militar. Tal vez es en este espacio de la academia donde se debe impulsar, es decir, replantear desde el mismo fuero interno del comandante la necesidad de cambiar de mentalidad para construir una institución que fortalezca la moral y ética militar, que concentre su desarrollo en la activa participación en la construcción y fortalecimiento de la paz.

Pero no es una tarea fácil y quizá para cumplirla sea necesario desaprender para aprender y reaprender. Quien ejerce el comando en el año actual (2020), vivió y sufrió el conflicto con todos sus horrores y vicisitudes, en su interior aún retumba el fragor del combate y los dolorosos recuerdos de sus compañeros caídos, así que el cambio no es sencillo y mucho menos inmediato. Así lo demuestra y afirma el general Ruiz Barrera (2014), presidente de la Asociación Colombiana de Oficiales 
Retirados (Acore), en una columna de opinión de la revista Semana: "Se equivocan quienes creen que en el posconflicto las Fuerzas Militares deben ser reestructuradas en cuanto a las funciones constitucionales". Es decir que desde los altos mandos hay reticencia al cambio, pues es evidente que el militar que hoy ostenta el mando se preparó, se formó y se desarrolló con parámetros orientados hacia la guerra.

Por esta razón los paradigmas de los comandantes se deben reestructurar. Si ellos no están preparados para el posconflicto, si no se hace con ellos procesos de concientización sobre ese nuevo concepto, no va a existir cambio porque el pensamiento de quien llega al cargo es que fue formado de cierta manera y, en consecuencia, las cosas se hacen de ese modo. Así las cosas, desde el mando la institución está por fuera de los conceptos de posconflicto, posacuerdo y paz, porque desde siempre se sigue haciendo referencia a prepararse para la guerra.

Algo similar ocurre en el caso de los docentes militares de la reserva. Si bien algunos tienen la posibilidad de compartir y ayudar a construir los saberes de los jóvenes militares por sus condiciones académicas, desempeño militar y liderazgo, el hecho de haber estado fuera del cuartel no significa que han olvidado que fueron parte de esa institución o que incluso han sido héroes de operaciones épicas, de modo que tampoco van a cambiar fácilmente.

Sin embargo, no se pretende tampoco que la academia militar sea liderada sin mayor consideración por jóvenes profesionales formados con la intención de contribuir al desarrollo de un país alejado de toda confrontación bélica y con nuevas mentalidades, idea que es a todas luces un error. El militar en formación requiere en su academia a los líderes precedentes porque a través de ellos conoce el pasado y desde ahí puede ver el presente y formarse como militar con proyección.

Aunque es innegable que la institución tiene el compromiso de modernizarse, estructurarse y desarrollarse pensando en un escenario inicial de posacuerdo y, posteriormente, de posconflicto, es necesario tener claro que se trata de un proceso lento, progresivo y que exige el apoyo de los altos oficiales, así como modificar paradigmas que han estado arraigados durante más de cincuenta años.

Por las razones que motivan su existencia, la educación castrense mantendrá un esquema rígido y regulado por el marco de la disciplina. De allí la importancia que tiene el docente, pues deberá asumir la responsabilidad de adecuar su cátedra a los nuevos escenarios planteados por la política del gobierno y dar cabida a la educación para la paz y el posconflicto. Además, en esta transformación deberá tener siempre presente que educar es un acto político, tal como afirma Freire en entrevista con Marín (1978) para El País: "Yo pienso que la educación es siempre un quehacer político. No hay, pues, una dimensión política de la educación, sino que ésta es un acto 
político en sí misma”, sin que esto lo exima de entender que un asunto es un acto político y otro el proselitismo y sesgo hacia determinada ideología.

En este sentido, el propósito actual de la formación del militar (prepararse para la guerra) se debe encaminar a cambiar el imaginario del militar guerrero y transformarlo en un militar ciudadano, promotor del desarrollo, entrenado en el respeto de los Derechos Humanos, el Derecho Internacional Humanitario (DIH) y la ley colombiana, sin dejar de lado la misión de la institución.

Toda esta reflexión evidencia que la educación militar amerita un reajuste, una reingeniería y un nuevo planteamiento que nazca desde su interior. Este sentir es precisamente el que ha orientado los nuevos diseños emanados desde la Doctrina Damasco ${ }^{4}$, a través de la cual se proyecta una institución que continúe siendo respetuosa del ordenamiento jurídico y de los Derechos Humanos, justa, cumplidora del DIH y orgullosa de ser la entidad que detenta las armas de la República, de tal manera que propenda por construir una sociedad en paz y se prepare para ella y no para la guerra.

Con esta perspectiva, el Plan de Transformación Ejército del Futuro (Petef) definió tres tiempos con plazo al 2030: el primero (2014-2018) es la etapa de estabilización, el segundo (2018-2022) comprende el periodo de transición y el tercero (2022-2030) consiste en la etapa multimisión, en la cual se consolidará un cuerpo de militares preparados para atender misiones relacionadas con el orden interno, la protección de la soberanía en las fronteras, participación en misiones internacionales y esfuerzos de apoyo en áreas importantes para la agenda mundial, como son el medioambiente y la atención de desastres (Centro de Educación Militar, 2018), y todo esto con un componente de educación, del cual no se puede desestimar el tema de la paz y el posconflicto. Este cambio es necesario en un escenario social que busca sustentar un proceso de paz, para lo cual es indispensable un periodo de transición interno del Ejército Nacional.

Aunque este planteamiento tiene sentido y se considera como el deber ser, aún es largo el camino por recorrer. Pretender que la institución se apropie y se constituya en la fuerza militar de un país sin conflicto es una utopía en este momento, pues no solamente persisten problemas de orden social, político y militar, sino que además aún existen grupos u organizaciones de delito transnacional que solo buscan aumentar las utilidades de las economías criminales que controlan por encima de la

4 "Doctrina que amalgama los principios fundamentales de las Fuerzas Militares que guiarán sus acciones en apoyo de los objetivos nacionales. Es la base de un nuevo comienzo para el Ejército de Colombia, el principio de la transformación y evolución de la institución [...] la pedagogía que a través de los Manuales Fundamentales del Ejército logrará la interoperabilidad, modernización con estándares internacionales que apuntan a solventar los retos actuales y garantizarán lo mejor de lo mejor en materia de seguridad y defensa”. 
Constitución y la ley. No cabe duda de que se deben enfrentar, pero entonces, ¿qué hacer? Precisamente ahí es donde está el problema, pues sin haber logrado la paz se quiere un Ejército educado y preparado para el posconflicto, pero con el compromiso de no descuidar la guerra contra nuevas amenazas emergentes.

\section{Redefinir los roles institucionales}

El primer paso en esta dirección es crear una verdadera educación para la paz. No se trata de una cátedra donde un general, coronel o disertante charle con los subalternos sobre el tema y sus percepciones particulares durante dos horas, medio día o un día. El campo de la educación ha demostrado durante más de trescientos ańos que es necesario planear las habilidades y competencias que se quieren desarrollar, hay que hacer prácticas... Es decir, generar una competencia para la paz exige mucho más tiempo, requiere que se integre al programa de la Escuela Militar de Cadetes "General José María Córdova” (ESMIC), cuando recibe a los cadetes; al de la Escuela de Suboficiales Sargento Inocencio Chinca (EMSUB) con los alumnos, y a las demás escuelas de formación y capacitación cuando reciben a los oficiales y suboficiales en los cursos complementarios y de ley. En últimas, que se vea una línea continua en la construcción de una educación para el posconflicto.

En este contexto, es importante revisar las funciones y tareas de las Fuerzas Militares y de la Policía Nacional: en Colombia el militar cumple tareas de policía y el policía se desempeña como militar. Esa yuxtaposición de responsabilidades y relación de tareas ha hecho que los roles se superpongan y se presenten, como es conocido, roces, celos profesionales, conflicto de intereses e incluso confrontaciones por el protagonismo en el desempeño de la misión.

Por esta razón es viable y posible que la Policía Nacional se desligue del Ministerio de Defensa y se adscriba al Ministerio del Interior, mientras los militares asumen el papel que les enmarca la Constitución Nacional en el artículo 217:

La Nación tendrá para su defensa unas Fuerzas Militares permanentes constituidas por el Ejército, la Armada y la Fuerza Aérea. Las Fuerzas Militares tendrán como finalidad primordial la defensa de la soberanía, la independencia, la integridad del territorio nacional y del orden constitucional. (República de Colombia, 1991)

No obstante, está comprobado 5 que las Fuerzas Militares salieron de los lugares que las otrora Farc como grupo insurgente habían abandonado con ocasión 2017, p. 5).

5 "Grupos armados ilegales y nuevos escenarios de riesgo en el posacuerdo" (Defensoría del Pueblo, 
del proceso de dejación de armas, pero la Policía Nacional no las ocupó. Como consecuencia, este vacío de autoridad fue aprovechado por otros grupos armados para apropiarse de estos lugares y desarrollar sus actividades delincuenciales.

Por esta razón, desde ninguna perspectiva y mientras persista la compleja situación de seguridad se puede disminuir el pie de fuerza, mucho menos los procesos de formación militar. Tampoco es posible asumir que el país está en "paz” y relajar el cumplimento de la ley. Sí es cierto que se firmó un acuerdo para terminar el conflicto y buscar la paz a través de una salida negociada, pero no se debe olvidar que fue con una sola de las organizaciones alzadas en armas, las demás persisten en la confrontación.

\section{Reforma de planes académicos y estructuras curriculares}

Para plantear cualquier tipo de cambio en la formación militar es válido considerar el siguiente análisis de Ospina (2010):

La educación para la paz y la educación para el conflicto tratan de alejarse de las nociones tradicionales de paz y de conflicto que ubica a ambos conceptos como dos opuestos en donde la paz es entendida como la ausencia de la guerra y los enfrentamientos bélicos y, por otra parte, los conflictos percibidos como un aspecto que se debe evitar si se pretende establecer la paz y la seguridad dentro de las sociedades. (p. 119)

Es decir, no se trata de polos opuestos, sino que por el contrario son factores convergentes y dinámicos, de manera que es necesario modificar metodologías, conceptos, paradigmas e incluso modelos de educación para lograr una transformación en las instituciones y en la sociedad. En este sentido, no se trata solamente de acatar las disposiciones para la paz establecidas en la Ley de Educación, las cuales señalan unos contenidos y programas a los que la institución militar les está dando "cumplimiento". Entre comillas porque no se crearon nuevos contenidos, sino que se acondicionaron algunas temáticas de acuerdo con la ley y se presume que se hace bien. La Cátedra de la Paz, por ejemplo, se ha estructurado en torno a un recorrido por la historia del conflicto y en algunos temas de los Derechos Humanos y el DIH, pero ha desdeńado lo más importante: la formación de valores y destrezas que requiere el militar para desempeñarse en una situación de posconflicto.

Frente a esta situación, algún militar podría plantear que es necesario reestructurar todo lo existente y partir de cero, pero no se trata de eso, como señala Escudero (1999): 
Educar para la paz, por consiguiente, no debiera traducirse en ańadir nuevos contenidos curriculares y específicos, sino en un determinado modo de abordar los contenidos existentes; un determinado estilo social de relaciones entre profesores y alumnos, así como de los alumnos entre sí; en un determinado enfoque que permita conectar lo que se enseña y corre en la escuela con la realidad social, cultural y política a la que pertenecen los alumnos y los mismos profesores. (p. 19)

Queda claro entonces que es posible articular lo que ya existe y esbozarlo de tal forma que potencie no solo los saberes, sino también el conocimiento de una realidad social, cultural y política en la cual está inmerso el militar. Asimismo, es importante considerar que el estudiante castrense debe tener el papel protagónico en el aula, para lo cual es necesario generar una pedagogía activa en la cual participe de manera integral en su proceso, dejando de lado prejuicios tradicionales sobre la forma de educarse en otras profesiones, tal como lo reseñan Hincapié et al. (2011):

La pedagogía activa concibe la educación como el señalar caminos para la autodeterminación personal, social y como el desarrollo de la conciencia crítica por medio del análisis y la transformación de la realidad; acentúa el carácter activo de los estudiantes en el proceso de aprendizaje, interpretándolo y orientando la experiencia de aula hacía ejercicios como buscar significados, criticar, inventar, indagar en contacto permanente con la realidad. (p. 53)

Desde esta perspectiva, la tarea consiste en llevar al estudiante militar a la realidad del acontecer nacional, sin condicionamiento alguno. Este cambio tiene que ser ahora mismo, no se puede esperar a que aparezca un modelo de educación para la paz para el militar, construido por advenedizos y que desconozca el ambiente de las Fuerzas Militares colombianas. En este sentido, un propósito de la educación militar para el posconflicto es contribuir a que la familia del militar y la sociedad estén alineadas en buscar la paz como un aporte a la construcción social, de manera que todos los individuos orienten sus actuaciones hacia el respeto del otro y la convivencia pacífica.

En Colombia hay una necesidad sentida y es que se deben formar militares con capacidades adecuadas y correspondientes a este proceso, que direccionen cada una de las propuestas de educación enmarcadas en la tradición e historia de una fuerza militar que ha sido el bastión sobre el cual se han soportado todos los ataques en contra de la democracia. En consecuencia, para estructurar un sistema de educación posconflcito dirigido a los militares se debe hacer un análisis amplio de las dimensiones sociales del militar y tener consideraciones de carácter sociocultural, antropológico, psicológico y económico. Es decir, no se trata simplemente 
de pretender estructurar algo nuevo, sino de pensar en el ser militar como tal y las implicaciones que traerán las modificaciones propuestas.

Asimismo, es importante tener en cuenta que la formación de orden castrense que recibe el militar se debe integrar mejor y a diario con la capacitación profesional o tecnológica complementaria, de tal manera que tenga la posibilidad de construir un proyecto de vida complementario cuando haya cumplido su servicio y pase al retiro. Así, en lugar de convertirse en un problema para la sociedad, podrá contribuir desde su nuevo papel a fortalecer la institucionalidad.

En este punto es importante mencionar la reflexión que hace Infante (2013) sobre la educación:

Casi siempre, un sistema educativo se encuentra estrechamente relacionado con un conflicto. Los sistemas educativos reproducen las habilidades, los valores, las actitudes y las relaciones sociales de los grupos dominantes en una sociedad; por tanto, con frecuencia son un factor que influye en el conflicto. (p. 232)

Este concepto es claro: no se puede separar la educación del conflicto porque el conflicto es la representación de lo que se vive en un lugar específico de la sociedad. Además, en el caso que nos ocupa, las Fuerzas Militares son un grupo representativo y reconocido en la sociedad como una de las instituciones de mayor aceptación.

Cabe señalar que las Fuerzas Militares plantearon dentro del Plan Estratégico del Sistema de Educación (Pese) varias estrategias, entre estas el Proyecto Educativo de las Fuerzas Armadas (Pefa), que determina los lineamientos ideológicos para crear un sistema educativo integral. El Pefa se instrumentaliza a través del Sistema Educativo de las Fuerzas Armadas (Sefa) y se ejecuta por medio del Plan Estratégico del Sistema Educativo (Pese), aparecidos a finales de 2008, en los cuales se hace referencia a misiones, tareas y escenarios correspondientes a una institución preparada y en proceso de transformación.

Esos documentos rectores de la educación, por así llamarlos, están enmarcados en la profesionalización militar, proceso que potencia el cumplimiento de valores como el honor, el deber, el patriotismo, la lealtad y la disciplina, apalancados en la vocación. Asimismo, se deben someter a cambios en el marco del posconflicto, de tal manera que estén inmersos en la formación militar y se haga estricto cumplimiento de lo que estipulan. Es decir, que no solo se quede en el papel, sino que se lleve a la realidad.

Específicamente, con la concreción del Pefa las Fuerzas Armadas de Colombia incorporaron las competencias del ser, del saber, del hacer y del convivir como pilares fundamentales de sus procesos educativos mediante una 
formación integral: ciudadanos con una sólida formación en principios, valores, virtudes y ética profesional; ejercitados en el arte de pensar, con el desarrollo del pensamiento complejo para alcanzar un sólido criterio militar o policial; profesionales con excelencia en la formación humanística, y ciudadanos ejemplares orientados al servicio de la comunidad, (pág. 21. 2008).

En consecuencia, la Escuela Militar de Cadetes "General José María Córdova” (ESMIC) debe repensar sus programas educativos porque actualmente el componente militar es el núcleo del proceso formativo, como lo señala el coronel Padilla (2013): "El $71 \%$ de la malla académica de la Escuela Militar está orientada a la formación de nuestros alumnos de manera que adquieran las competencias suficientes y necesarias para ser líderes eficientes en sus pelotones" (p. 11). Es decir, se sigue planteando la formación del militar para la guerra, para el combate y para la confrontación, mientras se deja de lado lo que se ha planteado en el mismo Pefa, es decir profesionales con formación humanística orientados a servirle a la sociedad.

Se necesita por tanto una reforma del pensum académico que pase de la formación militar para la lucha contra el terrorismo, contrainsurgente o contraguerrilla, como se quiera denominar, a un programa que se estructure en el cumplimiento de la misión que tiene cada una de las fuerzas según los mandatos constitucionales. Podría afirmarse entonces que la educación militar se sigue pensando en concordancia con las afirmaciones de Ospina (2010):

De manera frecuente, el concepto de educación para la paz suele ser entendido como un tipo de educación específicamente comprometida con el desarme, la reducción de armamentos y de gastos militares, la estrategia militar y el sistema de la guerra. (p. 115)

Es cierto, educar para la paz no es pensar en acabar el gasto militar, desarmar el componente legal de la seguridad del Estado, desarticular la estrategia. No, la educación para la paz y el posconflicto va mucho más allá de dar cabida a unos lineamientos académicos establecidos en la ley. Por el contrario, se trata de modificar los syllabus para cumplir los parámetros del Sefa en los ámbitos del ser, saber, hacer y convivir, así como involucrar las disposiciones sobre la paz y la reconciliación. Es decir, el reto consiste en diseñar una malla curricular innovadora que lleve de verdad a dar cumplimiento a los propósitos de la Cátedra para la Paz, determinados en el Decreto 1038, apropiándolos a los propósitos de la formación del militar colombiano. Asimismo, estructurar nuevas áreas de formación y entrenamiento para afrontar las amenazas emergentes globalizadas; al respecto preocupa, por ejemplo, la escasa formación en ciberseguridad, ciberdefensa y en el empleo de 
las Tecnologías de la Información y la Comunicación (TIC) aplicadas a la seguridad y defensa, aspecto que bien vale la pena potenciar.

También se deben enfatizar temas relacionados con la cooperación civil-militar, la asistencia humanitaria, la resolución de conflictos, el desarme, la desmovilización, la reinserción, las operaciones de mantenimiento de la paz, los Derechos Humanos y el DIH, la formación para observadores militares y la negociación. Si bien estos aspectos ya son parte de la formación que ofrece la institución militar, es fundamental que absolutamente todo el personal los conozca, participe y sobre todo los asimile, en especial pensando en el militar actual como un servidor público con alto sentido vocacional y respetuoso de la paz.

Desde esta perspectiva, un escenario que bien vale la pena explorar es el que se refiere a las tareas de apoyo al desarrollo de la comunidad, en el cual las Fuerzas Militares se preparan para reconstruir el país en beneficio del desarrollo económico. $\mathrm{Al}$ respecto, las experiencias de los batallones de construcciones de ingenieros militares son un eje de avance apropiado y ofrece amplios beneficios y reconocimiento social sobre las nuevas misiones del militar.

En ese orden de ideas la educación militar debe asumir un reto que ya estaba definido en en el Artículo 67 de la Constitución Nacional: "La educación formará al ciudadano en el respeto a los Derechos Humanos, a la paz y a la democracia”. De la misma manera lo indica el numeral 6 del Artículo 95: "Es un deber y obligación del Estado [...] propender al logro y mantenimiento de la paz". Estos parámetros constitucionales y otra legislación complementaria deben estructurar o reestructurar los currículos de la academia militar y asociarlos al cumplimiento legal para que sean adecuados a la misión que tienen las Fuerzas Militares en el contexto colombiano actual. De acuerdo con Escudero (1999),

la educación para la paz en el contexto del currículo no puede reducirse a un nuevo contenido curricular; no puede ser objeto de instrucción: por el contrario, la educación para la paz debiera ser un principio rector para analizar y guiar los procesos de enseñanza- aprendizaje. (p. 19)

Esto permite evidenciar la necesidad de promover unas estrategias de enseñanza de la paz, y de ellas hacer tránsito a la educación posconflicto, que se debe constituir en principio rector de la formación militar y reflejarse en todos los procesos educativos, sin menoscabo de la misión constitucional de la fuerza.

Esta formación posconflicto en la institución armada debe darse desde el inicio de la profesión militar, de manera que este ciudadano sea articulador de las necesidades de la sociedad, con una base firme de ética. En este sentido, no se 
trata de formar en saberes y capacidades bélicas, sino que se forma en escenarios en donde el propósito sea buscar la paz, y que esta sea un vivir, un sentir, un saber, un tener y un convivir.

Dentro de la modificación de las estructuras de la educación militar y pensando en un entrenamiento posconflicto, habrá que romper con ese corolario que se mantiene en la mente del militar, en especial cuando se está formando en la escuela de Fuerzas Especiales y demás centros de formación combatientes. Allí, en medio de la animación y el entusiasmo del trote, se hace referencia al poema ¡Piu Avanti!, de Almafuerte ${ }^{6}$, que en las escuelas de combatientes se recita a grito herido:

\title{
¡Piu Avanti!
}

\begin{abstract}
No te des por vencido, ni aun vencido, no te sientas esclavo, ni aun esclavo; trémulo de pavor, piénsate bravo, y arremete feroz, ya mal herido.

Ten el tesón del clavo enmohecido que ya viejo y ruin, vuelve a ser clavo; no la cobarde intrepidez del pavo que amaina su plumaje al menor ruido.

Procede como Dios que nunca llora; o como Lucifer, que nunca reza; o como el robledal, cuya grandeza necesita del agua y no la implora...

Que muerda y vocifere vengadora, ya rodando en el polvo, tu cabeza!
\end{abstract}

Es tan solo una referencia, no es la única al heroísmo, dominio, altruismo, superioridad y fortalecimiento del espíritu militar. No obstante, también incitan a la violencia, al atropello, al logro del objetivo pasando por encima de cualquier orden. En fin, este solo tema bastaría para elaborar todo un tratado.

Con referencia a lo anterior, cabe mencionar a Herrero (2003), cuando afirma que

si queremos que una educación para la paz sea posible en el sistema educativo, además de examinar las cuestiones didácticas y organizativas, debemos dedicar una atención especial a las cuestiones sociales, políticas y filosóficas que intervienen en el

6 Almafuerte es el seudónimo conocido de Pedro Bonifacio Palacios, que nació en San Justo, provincia de Buenos Aires, Argentina, en el año 1854. 
currículum. Es necesario replantear el currículum actual del sistema educativo para superar sus muchas violencias institucionalizadas. (p. 297)

En esa reflexión se enmarca lo que se debe replantear en la educación militar y en especial el tipo de educación que recibe el militar en el escenario de posconflicto.

\section{A manera de propuesta}

En el entendido que se da una mirada a la formación militar de cara al posconflicto, habría que considerar los postulados de López (2010), quien aduce, respecto a esta educación:

Podemos definir la pedagogía de la paz como el conjunto de teorías y prácticas educativas orientadas a la construcción de la paz a través de un modelo concreto de educación considerada como un proceso dirigido tanto a los individuos como a la sociedad para que actúen, conforme a los principios de la Cultura de Paz, respetando los derechos humanos, a favor del desarrollo sostenido de los pueblos, la protección y conservación del medio ambiente, la aspiración y acción en pro del desarme, del desarrollo y seguridad humana, el fortalecimiento de la convivencia social y la solución no violenta de los conflictos. (p. 2)

Es todo un complejo entramado de saberes que involucra a los individuos y la sociedad en la búsqueda de un ideal de convivencia en el cual se respeten los espacios culturales, sociales, ideológicos e incluso ambientales para la sana convivencia y la solución de los conflictos de manera no violenta.

Tomando como referencia que el objetivo principal de la Cátedra de la Paz, planteada en el Decreto 1732 de 2015, es

“crear y consolidar un espacio para el aprendizaje, la reflexión y el diálogo sobre la cultura de la paz y las escuelas que contribuya al bienestar general y el mejoramiento de la calidad de vida de la población”. Además se estipuló que debe ser un espacio reflexivo y de formación articulada con alguna de las siguientes áreas del conocimiento: Ciencias sociales, historia, geografía, constitución política y democracia. Ciencias naturales y educación ambiental. Educación ética y valores humanos.

Un aspecto notable que se ha trazado es no asumir la cátedra como una asignatura teórica, para no caer en el error de creer que con solo conocimientos los estudiantes aprenderán y desarrollarán capacidades como el respeto, la solidaridad, la empatía y el discernimiento necesarios para dirimir situaciones conflictivas de manera pacífica. Es decir, hay que complementarla con ejercicios prácticos de convivencia, labor social, visitas, diálogos con las comunidades, en fin, actividades en las 
cuales la dimensión teórica se plantee en espacios prácticos. Desde este contexto, el proceso educativo del posconflicto se constituye en un factor de desarrollo y convivencia para toda la comunidad que abre espacios de diálogo en busca de la paz.

Con base en estos referentes, a continuación, se presenta una propuesta que integra las categorías previstas con la ley que define la Cátedra para la Paz y que enfatiza los aspectos en que se han identificado carencias, falencias o dificultades:

1. En primer lugar, hay que ofrecer conocimientos básicos sobre la violencia que aqueja el país. Por ello, un contenido inicial o primer escenario es hacer un acercamiento al origen de la violencia en Colombia, precisando las definiciones básicas, para generar la claridad conceptual sobre bandolero, terrorista, grupo insurgente, insurrección, guerra, paz, conflicto, negociación, posacuerdo, posconflicto, reparación, verdad, justicia y, en general, todo el eje de los significados de todos los escenarios relacionados con la violencia, tomando como referencia la representación abstracta del tema reconocida mundialmente. Aunque este aspecto no lo contempla la ley, sí es importante que el estudiante desde su primera etapa de acercamiento al tema tenga los conceptos muy bien arraigados en su saber.

2. Adentrándose ya en el contexto, en segunda instancia se trabajaría la memoria histórica y la reconciliación, con lo cual se cumplirían los dos aspectos del decreto reglamentario: (1) memoria histórica, en la cual se involucran todos los temas afines con la historia del conflicto, sus orígenes, causas, hechos relevantes y todo el contexto que llevó a Colombia a una permanente guerra fratricida desde los albores de la Independencia: (2) historia de los acuerdos de paz nacionales e internacionales, los nacionales desde sus inicios, caracterizándolos y haciendo reconstrucción crítica de los aspectos positivos, los que dejaron vacíos y los que no fueron exitosos como medio de acercarse al conocimiento real de un conflicto de muchos años. Por su parte, los acuerdos de paz internacionales se abordarían de manera amplia con todo y las posibilidades de aprendizaje frente a la capacidad de entender instancias ajenas pero válidas, como ejemplo de superación de la conflictividad.

3. El tercer aspecto es la convivencia pacífica y, como parte de ella, la resolución pacífica de conflictos. Estos temas se abordarían desde la teoría y la casuística, estudiando casos relacionados con los conflictos bélicos que llegaron a feliz término a través de procesos resolutivos sin confrontación 
militar o armada. También se abordaría la prevención del acoso escolar, enfocado en el respeto por la dignidad del estudiante y los derechos que le asisten en su etapa escolar.

4. La cuarta categoría corresponde a la ética, el cuidado y las decisiones con los temas de Derechos Humanos, los cuales se abordarían desde las bases establecidas por los organismos internacionales y los acuerdos que el Estado colombiano ha firmado para su cumplimiento, así como todos los protocolos de protección creados y las normas y mandatos establecidos. Respecto a los dilemas morales, se entraría a discutir cada uno de los aspectos relacionados con la moral, desde lo político, religioso y demás caracterizaciones que actualmente se le da a la moral frente al comportamiento del individuo. Los últimos aspectos que abordaría esta categoría son los proyectos de vida y la prevención de riesgos: el primero se enfatizará en las dos variables frente a lo importante que es para el individuo tener claridad sobre su proyecto de vida en un contexto militar de amplia posibilidad de desarrollo y que trabaje en pro de obtener sus anhelos de orden personal. Con respecto a la prevención de riesgos cabe señalar que es un tema de amplio espectro para el ciudadano militar, en especial frente al riesgo que implica el uso de las armas y ser el representante de la violencia legítima que ejerce el Estado.

5. Por su parte, la quinta categoría se refiere a la convivencia y la paz. Esta última se concibe como una herramienta fundamental para el ser militar, pues por detentar las armas de la República y ser el único autorizado para ejercer el uso legítimo de la violencia, debe dar ejemplo ante la ciudadanía de su capacidad de convivencia y amplias alternativas de ayudar a que la paz sea el escenario ideal de integración social. En este sentido, el uso de la fuerza, el poder y la autoridad se debe dimensionar en relación con la responsabilidad constitucional del ser militar.

6. Este ítem señala que el militar se debe destacar por tener las herramientas adecuadas para afrontar la conflictividad, bien sea desde el ámbito operacional o incluso lo mínimo que se pueda presentar, en ese caso como mediador de situaciones que se presenten en el lugar donde está cumpliendo la misión. Para ello es indispensable que se forme en temas propios de la sociología y la antropología, de tal manera que sea líder y forjador de una sociedad incluyente e inclusiva con alta capacidad de entendimiento frente al comportamiento y las costumbres de los demás, aspecto que en el país genera enfrentamientos. 
7. La convivencia y la paz son escenarios de difícil comprensión, por ello el militar debe estar capacitado para valorar y aceptar con claridad que el país es un Estado compuesto por diversas culturas, tradiciones y contextos políticos, de los cuales debe tener un amplio bagaje de saberes para ser el facilitador del desarrollo de la comunidad en general. En este sentido, es preciso indicar que si bien conocer los contextos políticos, respetarlos y respetar a quien piensa diferente es una tarea inherente a la preservación de la sociedad, esto no quiere decir que el militar participe activamente en acciones o labores de orden político, pero si debe entender y tener claro que existen corrientes ideológicas variadas y todas han de respetarse siempre y cuando ejerzan su actividad de manera legal.

8. El militar formado y capacitado en temas de posconflicto y educación para la paz podrá desempeñarse acertadamente en cualquier unidad militar en la que sea destacado. A su vez, allí se convertirá en articulador y difusor de la política del Estado frente a la solución pacífica de los conflictos, además estará en capacidad de involucrarse de manera directa en todos los entornos sociales para recuperar el reconocimiento de las Fuerzas Militares por parte de la sociedad, el cual se ha perdido a causa del prolongado conflicto que ha vivido el país durante más de 60 años.

\section{Contenidos de la cátedra propuesta}

La primera etapa se debe enfocar en cumplir la Ley 1732 de septiembre de 2014, que establece la Cátedra para la Paz en todas las instituciones educativas del país, y el Decreto reglamentario 1038 del 25 de mayo de 2015, a través del cual se reglamenta la Cátedra de la Paz.

Además, se debe plantear el desarrollo sociohumanístico sin dejar de lado el campo militar, es decir, se plantea una formación que mantenga la alta exigencia de orden militar, pero con estándares de respeto por las emociones del otro, que se tenga consideraciones de respeto, disciplina y tolerancia. Ahora bien, es preciso señalar que el inicio en la vida militar se deberá entender como un fuerte choque emocional, por cuanto el individuo rompe con las rutinas de toda una vida de hogar y entra a formar parte de un estamento en el que las normas de comportamiento y disciplina son férreas por naturaleza, así que un primer escenario de acercamiento debe ser articular el currículo con contenidos que contemplen:

- Manejo de emociones.

- Competencias emocionales. 
- Competencias comunicacionales.

- Manejo de situaciones de conflictividad.

Asimismo, la Cátedra para la Paz aboga por comprender la justicia y los Derechos Humanos, aspecto fundamental para la convivencia pacífica de los ciudadanos, de tal manera que la propuesta debe contemplar:

- Derechos humanos.

- Derecho Internacional Humanitario.

- Protocolos internacionales.

- Tratados.

- Corte Interamericana de Justicia.

$\mathrm{Al}$ respecto de estos contenidos, Bobbio (2000) señala que "derechos humanos, democracia y paz son tres elementos necesarios del mismo movimiento histórico: sin derechos humanos reconocidos y protegidos no hay democracia; sin democracia no existen las condiciones mínimas para la solución pacífica de los conflictos" (p. 14). Este aspecto es de mucha importancia para el militar porque debe asumir responsabilidades ante el sistema de justicia internacional y cumplir los pactos acordados por el Estado colombiano.

Además de lo anterior, también hay que tener en cuenta los demás contenidos de la ley. De estos temas algunos ya son parte de la cátedra de formación, mientras que otros no se han abordado desde lo que representa para el militar colombiano:

\section{Memoria histórica.}

a. Violencia partidista de los años cincuenta.

b. Los grupos armados al margen de la ley.

c. Aparición de la cultura mafiosa.

d. Protección de las riquezas culturales y naturales del país.

e. Proyectos de impacto social.

2. Fenómenos de violencia reconocidos en Colombia.

a. Insurrecciones previas a la etapa de Independencia.

b. Independencia de la patria.

c. Luchas internas y enfrentamientos por el poder.

d. Aparición de partidos tradicionales y su incidencia en la violencia.

3. Resolución pacifica de conflictos.

a. Conflicto.

b. Procesos de negociación. 
4. Dilemas morales.

a. La ética.

b. Moral.

5. Historia de los acuerdos de paz nacional e internacional.

a. Acuerdos de paz de guerras mundiales.

b. Tratados de paz internacionales.

c. Acuerdos de negociación entre Estados.

d. Acuerdos de paz por conflictos internos.

6. Uso sostenible de los recursos naturales.

a. Protección del ambiente.

b. Legislación medioambiental.

7. Diversidad y pluralidad.

8. Participación política.

a. Conocimiento de ideas políticas.

b. Los partidos políticos en Colombia.

c. Nuevos movimientos y su desarrollo.

d. Pluralidad política.

Hasta ahí los temas de mayor impacto dentro de la institución militar. Los otros tres componentes o categorías determinados por la ley — participación ciudadana, diversidad e identidad, y desarrollo sostenible—son importantes y representan un campo nuevo y diferente para el militar, de manera que se tienen que asumirse con compromiso y liderazgo. Se podría decir que estos aspectos van de la mano con las propuestas del Comandante General de que el Ejército Nacional sea una fuerza militar multimisión. En dicho enfoque se integrarían estos tres temas, que son fundamentales para que las Fuerzas Militares desarrollen en el futuro las actividades de apoyo a la ciudadanía en general.

Ahora bien, dado que hasta este punto se ha hecho la presentación de una propuesta, a futuro es indispensable ampliar este trabajo con aspectos de orden estructural, particularmente sobre cómo se debería presentar el contenido de cada una de las materias.

No todo pasa por definir y afirmar que se va a cumplir y ser garante del acuerdo, de ahí que la Escuela de Armas Combinadas del Ejército Nacional señale en el libro Rol de las escuelas de las armas en el conflicto armado:

El más grande valor y desafío de la Escuela de Armas Combinadas del Ejército es, en la actualidad y hacia el futuro, llevar el conocimiento a nuestros hombres del rol que de hoy en adelante deberán cumplir como garantes del restablecimiento del orden institucional en el camino que afronta la nación del posacuerdo, tras 
la firma del acuerdo de paz con las Farc y cumpliendo la labor constitucional de mantenimiento de las disposiciones del Estado buscando la resolución de todos los conflictos, actuares de grupos delincuenciales y cualquier amenaza a la Constitución y las libertades dentro del Estado Social de Derecho. (p. 21)

No obstante, esta manifestación clara y contundente, es preciso continuar formando no el Ejército del futuro, sino el militar del presente, pues el futuro es incierto y el soldado del presente es quien tiene que estar atento al cumplimiento del acuerdo para la terminación del conflicto y la búsqueda de la paz, misión en la que la educación es un baluarte fundamental para su cumplimiento.

\section{Conclusiones}

El recorrido por los diferentes autores permitió obtener una visión sobre la necesidad sentida que tiene la institución militar de reestructurar la educación militar para que no solo se involucre directamente en el proceso de posconflicto, sino que cumpla el mandato de la legislación nacional con respecto a la educación para la paz.

Es necesario realizar una campaña amplia, profunda e incluyente que involucre todos los entes educativos militares, sus directivos y en especial a los docentes, en la cual se socialicen las directrices no solo de lo contemplado en educación con relación al posconflicto, sino también de la obligación de cumplir el mandato de ley con respecto a los contenidos curriculares.

Es la oportunidad de desarrollar un nuevo proyecto o Plan Estratégico del Sistema Educativo de las Fuerzas Armadas (Pese), considerando que la vigencia del existente era de 2007 a 2019. Es decir, es necesario hacer una profunda revisión para acondicionar el sistema educativo militar a los nuevos escenarios de la patria.

El compromiso de cambio debe estar en cabeza y articulado desde las alma máter del Ejército, a saber, la Escuela Militar de Cadetes José María Córdova, la Escuela de Suboficiales Sargento Inocencio Chinca y la Escuela de Soldados Profesionales Soldado Pedro Pascasio Martínez Rojas, cuna del proceso formativo del militar colombiano, y de ahí diseminar hacia las demás escuelas de capacitación y entrenamiento para que exista unidad de criterio y, en especial, convencimiento de los nuevos retos educativos y formativos del militar colombiano.

\section{Agradecimientos}

Esta investigación ha sido realizada gracias al apoyo de la Escuela de Armas Combinadas del Ejército (Esace), bajo la dirección del señor Coronel Andrés 
Mauricio Quintero Londońo. El autor declara que no existe ningún potencial conflicto de interés relacionado con el capítulo.

\section{Financiación}

El autor no declara fuente de financiación para la realización de la presente investigación.

\section{Referencias}

Ahumada P., M. A. (2007). El enemigo interno en Colombia (1. ${ }^{a}$ ed.). Quito: Abya-Yala.

Bobbio, N. (2000). El tiempo de los derechos (trad. Rafael de Asís Roing). Madrid: Sistema.

Borrero, C. \& Alfonso, S. J. (2006). Educación y politica. La educación en lo superior y para lo superior El maestro. (t. 5. Historia universitaria: enfoques universitarios). Bogotá, D. C.: Universidad Javeriana.

Centro de Educación Militar [Cedoe]. (2018). Rol de las escuelas de las armas en el conflicto Armado. Bogotá, D. C. Ejército Nacional de Colombia.

Escudero M., J. M. (1999). El desarrollo del currículum y la educación para la paz. Pedagogía Social: Revista Interuniversitaria, (5), 5-21. Recuperado de https://dialnet.unirioja.es/servlet/articulo?codigo $=2577061$

Fisas, V. (1998). Una cultura de paz. En Cultura de paz y gestión de conflictos. Barcelona: Icaria y Unesco.

Freire, P. (2006). Pedagogía de la esperanza. Un reencuentro con la pedagogía del oprimido. Madrid: Siglo XXI.

Guerrero, N. \& Osorio, C. C. (2017). La convivencia escolar en el plan de desarrollo Bogotá Humana 2012-2016: una aproximación desde la investigación documental (Trabajo de especialización). Universidad Distrital Francisco José de Caldas, Facultad de Ciencias de la Educación. Bogotá, D. C., Colombia.

Herrero, R. S. (2003). Reseña de "Educación para la paz. Su teoría y su práctica” de Xesús R. Jares. Convergencia. Revista de Ciencias Sociales, 10 (33), 285-298.

Hincapié, F., Rojas, M. C., Gallego, E. \& Ledesma, M. E. (2011). Concepciones de enseñanza que tienen los profesores de educación superior de programas presenciales y a distancia. Revista Teoria y Praxis Investigativa, 6 (1), 47-57.

Infante, A. (2013) El papel de la educación en situaciones de posconflicto: estrategias y recomendaciones. Revista Hallazgos, 11 (21), 223-245.

Klepak, H. (2012). Formación y educación militar: los futuros oficiales y la democracia. Buenos Aires: Resdal.

López Martínez, M. (2010). Pedagogía y paz. España: Instituto de la Paz y los Conflictos de la Universidad de Granada.

Marín, K. (mayo 19 de 1978). Entrevista a Paulo Freire: "La educación es siempre un quehacer político". El Pais. Recuperado de https://elpais.com/diario/1978/05/20/sociedad/264463223_850215.html 
República de Colombia. (1991). Constitución Política de Colombia. Recuperado de http://www. secretariasenado.gov.co/senado/basedoc/constitucion_politica_1991.html

República de Colombia. (2014). Ley 1732 de 2014. Por la cual se establece la Cátedra de la Paz en todas las instituciones educativas del país. Diario oficial, No. 49261. Recuperado de http:// www.suin-juriscol.gov.co/viewDocument.asp?ruta=Leyes/1687408

Ministerio de Defensa. (2008). Plan Estratégico del Sistema Educativo de las Fuerzas Armadas 20072019 (Pese). Bogotá, D. C.: Pro-offset.

Oficina del Alto Comisionado para la Paz. (2016). Acuerdo final para la terminación del conflicto y la construcción de una paz estable y duradera (1. ${ }^{\mathrm{a}}$ ed.). Bogotá, D. C. Imprenta Nacional.

Organización de las Naciones Unidas [ONU]. (1984). Declaración Universal de los Derechos del Hombre [documento en línea]. Recuperado de https://www.un.org/es/documents/udhr/ UDHR_booklet_SP_web.pdf

Ospina, J. (2010) La educación para la paz como propuesta ético-política de emancipación democrática. Origen, fundamentos y contenidos. Universitas. Revista de Filosofia, Derecho y Politica, (11), 93.125. Recuperado de http://universitas.idhbc.es/n11/11-07.pdf

Padilla, J. M. (2013). Editorial. Revista Armas y Letras, (57), 8.

Rettberg, A. (ed.) (2012). Construcción de paz en Colombia. Bogotá, D. C.: Universidad de los Andes.

Ruiz, B. J. (mayo 2 de 2014). Nuestras Fuerzas Armadas en el posconflicto. Revista Semana. Recuperado de http://www.semana.com/opinion/articulo/fuerzas-armadas-en-el-postconflicto-opinion-del-general-r-jaime-ruiz/385666-3

Schultze-Kraft, M. (2012). La cuestión militar en Colombia: la Fuerza Pública y los retos de la construcción de la paz. En Angelika Rettberg (ed.), Construcción de paz en Colombia (pp. 405-443). Bogotá, D. C.: Universidad de los Andes.

Ugarriza, J. E. (2013). La dimensión política del postconflicto. Avances conceptuales y empíricos. Colombia Internacional, (77), 141-177. Recuperado de http://www.scielo.org.co/pdf/rci/n77/ n77a06.pdf

Vergara M. (2016) La práctica docente. Un estudio desde los significados. Revista Cumbres, (2), 73-99.

Villegas González, H. (2014). Educación para la paz, una obligación institucional. Entrevista con Gloria Ramírez Hernández [documento en línea]. Recuperado de https://www.cch.unam.mx/ comunicacion/sites/www.cch.unam.mx.comunicacion/files/subidas/eutopia_20.pdf

Zurbano, JL. (1998). Bases de una educación para la paz y la convivencia. Navarra: Graficas Ona. 